\title{
Pengembangan Desain Mesin Penghancur Kotoran Kambing Dengan Menggunakan Metode QFD
}

\author{
Sanny Andjar Sari ${ }^{1}$, Prima Vitasari $^{2}$, Salammia $\mathbf{L A}^{3}$ \\ 1 Teknik Industri, Institut Teknologi Nasional Malang \\ 2 Teknik Industri, Program Pascasarjana, Institut Teknologi Nasional Malang \\ 3 Teknik Industri, Institut Teknologi Nasional Malang \\ * E-mail sesuai dengan: sannysari@lecturer.itn.ac.id
}

\begin{abstract}
Abstrak
Pada umumnya pembuatan pupuk kandang yang terbuat dari kotoran kambing ini memerlukan bahan tambahan seperti : Fermentator, air, daun kering dan juga menggunakan alat seperti : cangkul, plastik, ember, terpal dan penumbuk. Proses pembuatan pupuk kandang yang telah dilakukan para petani di desa Ngadirejo Kecamatan Kromengan ini tentunya memerlukan waktu yang lama untuk menjadikan kotoran kambing sebagai pupuk, hal ini disebabkan pada proses penghancuran kotoran kambing yang sudah kering ditumbuk secara manual. Tujuan penelitian ini yaitu merancang mesin penghancur kotoran kambing untuk mengoptimalkan proses penghancuran kotoran kambing. Metode yang digunakan untuk merancang mesin penghnacur kotoran kambing yaitu dengan metode Quality Function Deployment (QFD). QFD adalah suatu pendekatan untuk mendesain mesin agar dapat memenuhi keinginan pengguna dalam hal ini peternak kambing. Berdasarkan keinginan pengguna yang diperoleh dari kuesioner diperoleh atribut rancangan, setelah itu ditentukan respon teknis rancangan. Langkah selanjutnya adalah membuat visualisasi rancangan dan prototype mesin. Mesin yang dirancang kemudian diujicoba terhadap responden, hasilnya responden merasa nyaman dan lebih mudah untuk dioperasionalkanDengan menggunakan mesin penghancur kotoran kambing ini akan memudahkan para petani untuk membuat pupuk organik dengan waktu yang lebih singkat atau lebih cepat dari pada sebelumnya.
\end{abstract}

Kata kunci : Mesin Penghancur, Kotoran Kambing, QFD

\section{Pendahuluan}

Pada umumnya pembuatan pupuk kandang yang terbuat dari kotoran kambing ini memerlukan bahan tambahan seperti : fermentator, air, daun kering dan juga menggunakan alat seperti : cangkul, plastik, ember, terpal dan penumbuk. Dalam pembuatannya ini menggunakan 50kg kotoran kambing untuk luas lahan 25m2.Pembuatan pupuk organik ini kotoran kambing di letakkan di atas terpal selanjutnya fermentator yang telah di campur air dalam ember di siramkan ke tumpukan kotoran kambing di aduk menggunakan cangkul secara berkala $3-4$ kali pengadukan hingga merata.Proses pembuatan pupuk kandang yang telah dilakukan para petani di Desa Ngadirejo Kecamatan Kromengan ini tentunya memerlukan waktu yang lama untuk menjadikan kotoran kambing sebagai pupuk, ini disebabkan kotoran kambing yang sudah kering dihancurkan secara manual. Sehingga membutuhkan waktu yang lama.

Pada penelitian ini akan dibuat mesin penghancur kotoran kambing yang utamanya sesuai dengan kebutuhan pengguna dalam hal ini petani, yaitu dengan menggunakan metode Quality Function Deployment (QFD), dimana Quality Function Deployment (QFD) adalah suatu metode perencanaan dan pengembangan produk yang terstruktur, untuk menentukan secara jelas kebutuhan konsumen yang diinginkan dan kemudian melakukan perhitungan secara sistematis, pada akhirnya menghasilkan produk yang dapat memuaskan konsumen (Cohen, 1995). Secara umum dapat 
dikatakan bahwa QFD merupakan suatu sistem pengembangan produk mulai dari proses perancangan produk, proses pembuatan produk hingga produk tersebut diterima konsumen dan seluruhnya didasarkan atas keinginan konsumen (Widodo, 2005).

Dengan menggunakan alat penghancur kotoran kambing ini akan memudahkan para petani untuk membuat pupuk kandang dengan waktu yang lebih singkat atau lebih cepat dari pada sebelumnya.

Kebutuhan akan pupuk yang semakin meningkat akan tetapi harga pupuk kimia yang semakin mahal, hal tersebut yang memotivasi para petani untuk memanfaatkan hasil limbah peternakan kambing yang ada di desa Ngadirejo Kecamatan Kromengan Kabupaten Malang tersebut sebagai bahan baku pupuk kandang. Dimana kondisi saat ini para petani sangat membutuhkan mesin untuk proses penghancuran kotoran kambing yang digunakan sebagai bahan baku pupuk kandang .

\section{Metode Penelitian}

Data yang diperoleh diolah dan dianalisis dengan menggunakan metode QFD dengan tahapan :

- Tahap 1 - Menentukan Atribut Produk Mesin Penghancur Kotoran Kambing

Berdasarkan survey mengenai keinginan pengguna terhadap produk dan menanyakan melalui wawancara untuk menentukan importance rating berdasarkan skala likert dengan skala 1 sampai 5, dimana angka 1 menunjukkan least important dan angka 5 menunjukkan most important.

- Tahap 2 - Engineering Characteristics

Rancangan produk baru dijabarkan dalam pengertian karakteristik/parameter teknis dimana dapat didasarkan pada spesifikasi teknis produk atau menurut operasionalisasi dari atribut-atribut produk yang ada.

\section{- Tahap 3 - Interaction Matrix}

Inti dalam metode QFD adalah hubungan antara atribut-atribut produk (what) dengan parameter teknis (how). Evaluasi dari setiap sel matriks yang menunjukkan apakah hubungan kuat-erat $($ strong $)=9$, sedang $($ medium $)=3$, lemah $($ weak $)=1$ atau tidak ada hubungannya sama sekali.

Jumlah skor untuk tiap-tiap parameter teknis (per kolom matriks) akan menunjukkan prioritas yang harus diambil dari proyek perbaikan rancangan.

\section{- Tahap 4 - Interaction Between Parameters}

Perubahan sebuah parameter akan mempengaruhi hubungan dengan parameter yang lain. Hal penting yang perlu ditetapkan terlebih dahulu adalah derajat hubungan antara parameterparameter yang ada sebelum mengembangkan solusi alternatif untuk perbaikan satu atau lebih dari parameter-parameter teknis dari produk secara spesifik. Bagian ini merupakan posisi atap dari rumah kualitas (roof of QFD).

- Tahap 5 - Technical Analysis \& Target Values

Pada tahap ini desain produk lama dengan produk kompetitor - yang dijadikan acuan untuk "benchmarking" - dianalisis, diperbandingkan dan dievaluasi untuk menetapkan nilai-nilai parameter teknis yang perlu memperoleh perhatian untuk perbaikan produk.

Langkah ini akan memberikan kemungkinan untuk langkah perbaikan serta penetapan "target values" yang harus bisa dipenuhi oleh rancangan produk yang akan dikembangkan.

\section{Hasil dan Pembahasan}

Pengumpulan data disini dilakukan dengan penelitian survey.Quality Function Deployment merupakan sebuah alat perencanaan yang digunakan untuk memenuhi harapan konsumen terhadap produk.Alat perencanaan utama dalam matriks Quality Fuction Deployment adalah House of Quality (HOQ). Kuisioner dibagikan kepada 30 orang yang semuanya adalah peternak pembuat pupuk kandang yang terkoordinir dalam Kelompok Tani Makmur di desa Ngadirejo Kec.Kromengan Kab. Malang. Kuisioner ini merupakan kuisioner yang dilakukan untuk mengetahui keinginan para peeternak terhadap mesin untuk yang sesai kebutuhan untuk membuat pupuk kandang.Kuisioner ini terdiri atas 2 bagian, yaitu bagian pertama berupa kebutuhan peternak, bagian kedua berupa tingkat 
kepentingan dan kepuasan peternak (responden) dengan adanya mesin penghancur kotoran kambing dengan melihat dari berbagai segi.

Adapun faktor-faktor dan formula yang dibutuhkan dalam pengolahan data tersebut dapat diuraikan sebagai berikut:

a. Variabel kebutuhan konsumen terhadap produk, seperti Fungsi, Estetika, Durability, Keamanan, Ergonomis, Ketersediaan partsdan Ekonomis.

b. Tingkat kepentingan konsumen.

c. Evaluasi produk.

d. Penentuan Nilai Target.

\subsection{Menentukan Atribut Mesin Penghancur Kotoran Kambing}

Dari hasil survey dan penyebaran kuesioner, diperoleh daftar keinginan dan kebutuhan konsumen terhadap mesin penghancur kotoran kambing, untuk menentukan importance rating berdasarkan skala likert dengan skala 1 sampai 5, dimana angka 1 menunjukkan least importance dan angka 5 menunjukkan most importance, seperti dapat terlihat pada tabel berikut.

Tabel 3.1. Atribut Kebutuhan Responden

\begin{tabular}{llc}
\hline No & Atribut & $\begin{array}{c}\text { Tingkat Kepentingan ( } \\
\text { Importance Rating) }\end{array}$ \\
\hline 1 & Proses penghancuran cepat & 5 \\
\hline 2 & Hasil penghancuran halus & 5 \\
\hline 3 & Mudah dioperasikan & 5 \\
\hline 4 & Mudah perawatan & 4 \\
\hline 5 & Hemat biaya & 4 \\
\hline 6 & Tidak ada bagian alat yang berbahaya & 3 \\
\hline 7 & Tahan lama & 5 \\
\hline 8 & Mudah penggantiankomponen & 4 \\
\hline 9 & Mesin mudah dipindahkan & 3 \\
\hline
\end{tabular}

\subsection{Kebutuhan Teknis (Technical Requirement) dan Nilai Sasaran (Objective Values)}

Langkah berikutnya adalah menyusun kebutuhan teknis yang sesuai dengan kebutuhan konsumen. Dari kebutuhan teknis tersebut dapat ditentukan nilai sasaran yang ingin dicapai untuk tiap-tiap kebutuhan teknis alat tersebut. Kedua komponen tersebut dapat dilihat pada matriks house of quality.

\subsection{Interaction Matrix}

Inti dalam metode QFD adalah hubungan antara atribut-atribut produk (what) dengan parameter teknis (how). Evaluasi dari setiap sel matriks yang menunjukkan apakah hubungan kuat-erat (strong) $=9$, sedang $($ medium $)=3$, lemah (weak) $=1$ atau tidak ada hubungannya sama sekali.

Jumlah skor untuk tiap-tiap parameter teknis (per kolom matriks) akan menunjukkan prioritas yang harus diambil dari proyek perbaikan rancangan.

\subsection{Interaction Between Parameters}

Perubahan sebuah parameter akan mempengaruhi hubungan dengan parameter yang lain. Hal penting yang perlu ditetapkan terlebih dahulu adalah derajat hubungan antara parameter-parameter yang ada sebelum mengembangkan solusi alternatif untuk perbaikan satu atau lebih dari parameterparameter teknis dari produk secara spesifik. Bagian ini merupakan posisi atap dari rumah kualitas (roof of QFD). 


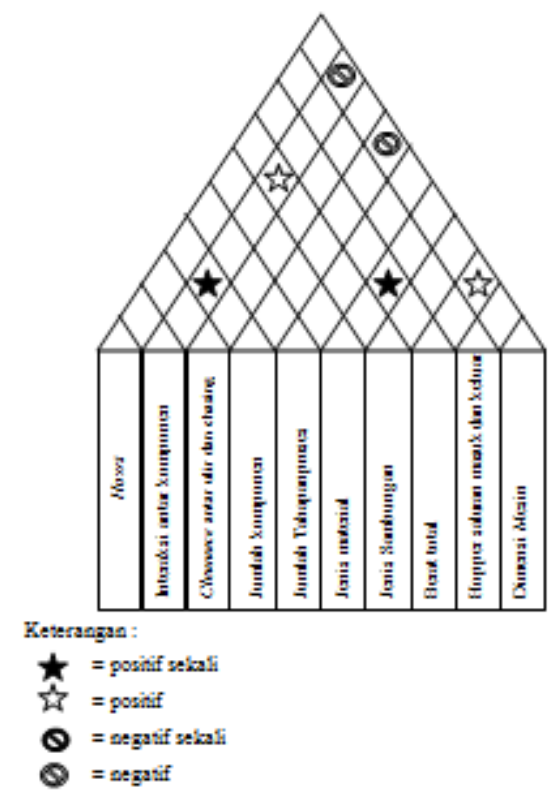

Gambar 1. Interaction Between Parameters

\subsection{Technical Analysis \& Target Values}

Pada tahap ini desain produk lama dengan produk kompetitor - yang dijadikan acuan untuk "benchmarking" - dianalisis, diperbandingkan dan dievaluasi untuk menetapkan nilai-nilai parameter teknis yang perlu memperoleh perhatian untuk perbaikan produk.

Langkah ini akan memberikan kemungkinan untuk langkah perbaikan serta penetapan "target values" yang harus bisa dipenuhi oleh rancangan produk yang akan dikembangkan. Bagian ini berada pada bagian bawah bagan QFD.

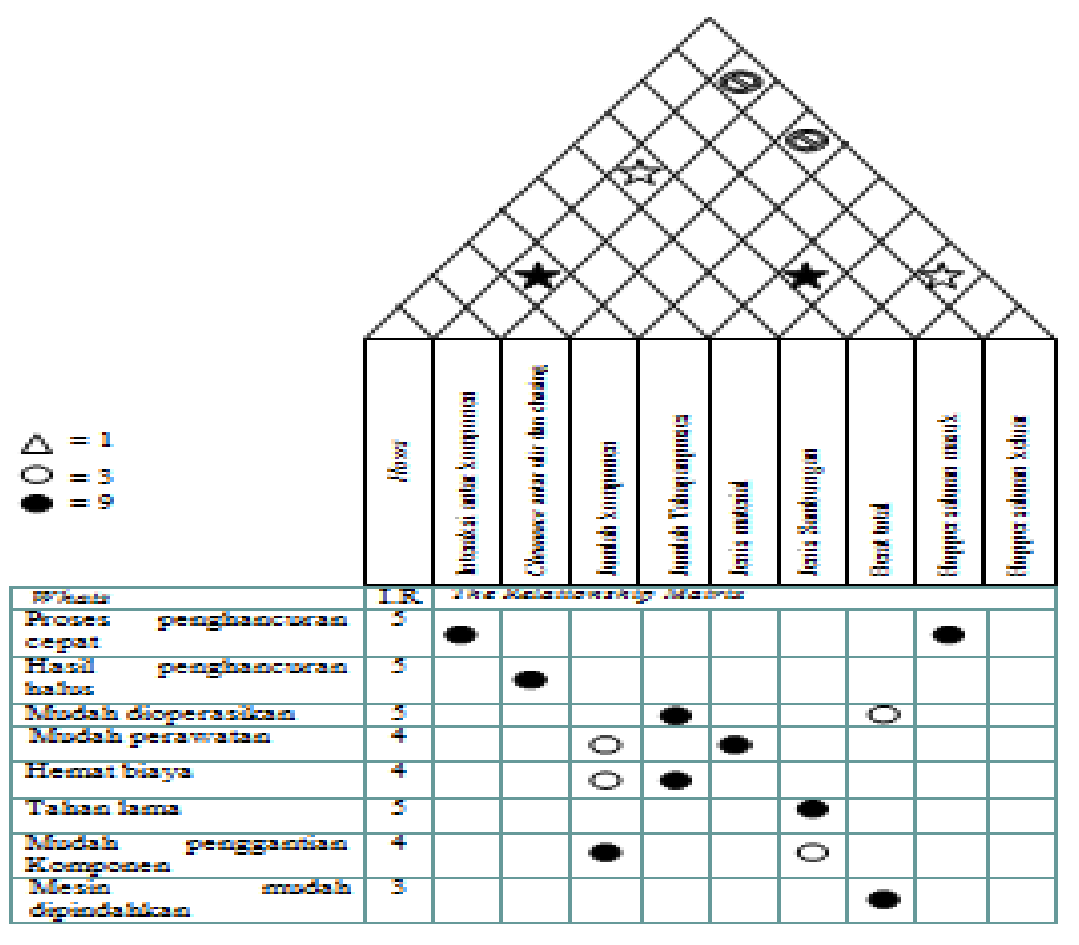




\subsection{Final Desain Mesin Penghancur Kotoran Kambing Sebagai Pupuk Organik}

Desain mesin penghacur kotoran kambing sebagai pupuk organik ini mengutamakan mekanisme yang sederhana, praktis, nyaman dan mudah dalam pengoperasiannya serta sesuai dengan prinsip-prinsip ergonomi.

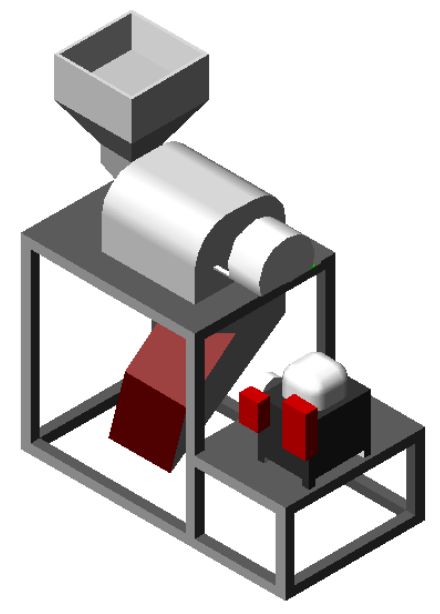

Gambar 2. Desain Mesin Penghancur Kotoran Kambing

Mesin ini memiliki dimensi panjang $710 \mathrm{~mm}$, lebar $690 \mathrm{~mm}$, dan Tinggi $980 \mathrm{~mm}$. Dengan spesifikasi sebagai berikut

1. Mesin Bensin.

2. Kapasitas $5 \mathrm{~kg}$.

3. Mudah dalam perawatan maupun perbaikan mesin tersebut.

Adapun sistem kerja atau operasional mesin penghancur kotoran kambing sebagai pupuk organik ini adalah sebagai berikut :

a. Operator menghidupkan mesin untuk proses penghancuran kotoran kambing.

b. Operator menyiapakan wadah untuk menampung hasil dari penghancuran kotoran kambing.

c. Operator memindahkan kotoran kambing yang sudah kering kedalam hopper mesin penghancur.

d. Hasil dari penghancur tadi kemudian dimasukan kedalam karung.

e. Setelah semua pekerjaan selesai, mesin dapat dimatikan

Sedangkan untuk proses baru ini menggunakan mesin yang digerakkan menggunakan mesin bensin yang fungsinya untuk mempercepat proses pengerjaan dalam pembuatan pupuk organik yang nantinya akan di pakai dilahan pertanian tersebut. Hal ini akan mempermudah petani dalam proses penghancur kotoran kambing sebagai pupuk organik.

\section{Kesimpulan}

Dari hasil kegiatan penelitian yang telah dilaksanakan memberikan kesimpulan :

1. Operasional mesin penghancur kotoran kambing sabagai pupuk organik ini lebih efisien dan lebih ergomonis di bandingkan dengan mesin lama ( cara manual ).

2. Desain mesin penghancur kotoran kambing sebagai pupuk organik menciptakan rasa aman dan nyaman bagi operator kerja.

3. Dari mesin penghancur kotoran kambing yang baru memiliki panjang $71 \mathrm{~cm}$, lebar $45 \mathrm{~cm}$, dan tinggi $98 \mathrm{~cm}$ diperoleh waktu normal sebesar 3,05 menit / kg sehingga menghasilkan output standard sebesar $20 \mathrm{~kg} / \mathrm{jam}$. Dengan melihat data-data yang diperoleh jadi didapat kenaikan persentase sebesar $900 \%$. 


\section{Daftar Referensi}

[1] Cohen, Lou, 1995, Quality Function Deployment "How To Make QFD Work For You", Addison-Wesley Publishing Company One Jacob Way.

[2] Charles Anson,2006. Desain Dan Pembuatan Alat Penggiling Daging Dengan Quality Function Deployment. Jurusan Teknik Industri, Fakultas Teknologi Industri, Universitas Kristen Petra.Surabaya.

[3] Pascalis Yulian,2010. Perancangan Alat Penghancur Bahan Pewarna Alami Dengan Pendekatan Metode Rasional Untuk Meningkatkan Produksi Pewarna Alami

[4] Tamara, Priscilla, 2016, Pengembangan Model Tungku Pelebur Limbah Kaca Dengan Metode QFD DAN AHP.Proceeding SENATEK,Malang.

[5] Ulrich, Karl T. and Steven D, Eppinger. 2001. Perancangan dan Pengembangan Produk. Jakarta: Salemba Teknik.

[6] Widodo, Imam Djati, 2005, Perencanaan dan Pengembangan Produk, UII Press, Yogyakarta.William Mendenhall, Statistics for engineering and The Sciences, third edition, Universitas of South Florida. 